\section{Schlafbezogener Laryngospasmus}

Helga Peter

Marburg, Deutschland

\section{Englischer Begriff}

sleep related laryngospasm

\section{Definition}

Die Störung führt zum abrupten Erwachen aus dem Schlaf mit Atemnot bei ausgeprägtem Stridor. Häufig werden die Patienten dabei zyanotisch und springen aus dem Bett. Die Episoden kommen nur wenige Male im Jahr vor. Assoziationen mit > „Gastroösophagealer Reflux“ und mit $>$,Obstruktive Schlafapnoe“ sind bekannt. Differentialdiagnostisch abzugrenzen sind die "Erstickungsanfälle im Schlaf“ (sleep related choking), die nicht mit Stridor oder Cyanose einhergehen.

Die Störung wird in der „ICSD-3“ in Appendix A kategorisiert als „Schlafbezogene körperliche und neurologische Erkrankung“. 